used. From density measurements on these regions a curve relating density to exposure can be drawn. This usually yields a straight line up to a density of about 1.5.

Mr. Stokes raised the important question of the effect of the size of the slit of the microdensitometer. The error introduced can be corrected by formula. In this connexion figures were given for the variation of observed density due to the graininess of the photographic material. The variations are appreciable, and it was pointed out that the height of the densitometer slit is limited by the fact that the spectral lines are curved, particularly at large angles of reflexion.

Another interesting point concerns the difference between the appearance of the X-ray spectrum and the recorded trace. A slide was shown illustrating a series of spectral lines and the corresponding density trace. The appearance of one of the lines suggested that there were two lines close together, one being much denser than the other. The densitometer trace revealed that the less dense 'line' was no more than a barely significant shoulder on the record of the line. The second peak was, in fact, not a peak at all, but merely an indication of the existence of a point of inflexion in the density trace. The slide showed the method of taking account of the fog or background which is nearly always present and usually increases towards the position -of zero deflexion of the ineident beam. It is usually possible on the density trace to draw a smooth line passing through the minimum density positions.

The use of photographic photometry in quantitative spectrum analysis was dealt with by Mr. Smith. The spark spectra of metals or alloys containing small quantities of impurities are recorded photographically, the most important region being in the ultraviolet from about $2,300 \mathrm{~A}$. to 4,500A. Spectrum analysis is most useful when the impurities are present in amounts less than about 2 per cent. The principle of the method is that the intensity of an impurity line is related to the intensity of a basis metal line according to the percentage impurity present. The procedure is to prepare a series of standards containing known quantities of impurity, and, by comparing the relative densities of basis metal and impurity lines, to determine the percentage corresponding with the relative densities obtained from the test sample.

Accurate calibration of the plate presents difficulties peculiar to the problem. Since a light source similar in constitution to the test source is required, a spark source is indicated; but unfortunately this is variable in both intensity and in the relative intensities of the different lines. The simplest and probably the most accurate method is to photograph a range of standards samples on each plate; but this has the disadvantage that it leaves less room for test exposures, it rapidly consumes carefully prepared and analysed standards and it appreciably increases the time taken. Another method is to use a rotating stepped sector in front of the slit. This method yields an intermittent calibrating exposure, but it has been claimed that this is permissible provided the sector disk is rotated at a rate of $200-300$ r.p.m. The intermittency effect can be overcome by using a stepped density wedge in place of the sector shutter, but this has been little used owing to the difficulty of obtaining satisfactory densities which are neutral over the requisite wave-length range.

Mr. Smith believes that the chief sources of error lie in the inconsistency of the light source, and that errors in the photographic process play a relatively unimportant part. He hopes that the reproducibility of the source will be improved in the near future.

Some discussion took place after the papers in which questions of detail were asked. Mr. L. V. Chilton agreed that photographic photometry has its difficulties and that a complete understanding of the principles involved is essential to success. On the other hand, microphotometry has its own particular difficulties, and though some of the speakers had indeed dealt with certain aspects, there are many interesting points peculiar to this field which could profitably be discussed in detail.

\section{THE FOREST AS A FACTORY}

\section{By Prof. E. P. STEBBING University of Edinburgh}

TN a memorandum written for a Government conference last summer, I made the statement that the forest is a "factory" just as much as a factory turning out tanks or aeroplanes. The statement appeared to create some surprise. Let us consider how it may be justified though, with the exception of India, inadequately recognized in that great organization the British Empire and Commonwealth of Nations.

We will first look at India; in spite of the fact that many heads of the other forest services hold that Indian forestry conditions, with all their great range of climate, soils, species, plains and mountains, are not applicable to conditions outside that country. During the War of 1914-18, India very soon found herself, owing to deficient shipping, deprived of many imported goods and left to her own resources. The forests, with an adequate forest staff for the purpose, were soon called upon to supply large military and civil requirements ; and the young Forest Research Institute played a remarkable part in assisting in this matter. This is familiar history. Once again, in the present War, the same position has had to be faced in India on an even larger scale. Once again her forests, having been under a conservative management for just eighty years, under an adequate forest staff and assisted by one of the biggest and best equipped forest research institutes in the world, have proved adequate to the call upon their resources.

An examination of some of the War publications from the latter, Records, Bulletins and Leaflets, prove, if proof be necessary, that the forest is merely a giant factory which in combination with the work of the research officer (for example, in an aircraft factory where the combination is now fully recognized) can face new demands, provided a sufficiency of labour is available. Examples of this work have already been given in these columns (NATURE, 153, 201 ; 1944). They furnish evidence of how research, with the forest to provide the necessary raw materials, was able to come to the assistance of the Fighting Services, as well as civilians, when imports of many kinds ceased. The research part of the 'factory' solved the problem of finding a substitute article for the one which could no longer be imported; the 'forest factory', according to location of supplies, well known to an organized department, provides the raw material ; and the third 'factory' in the business, the only one recognized by so many, makes up the article. But the third would have been non-existent 
had not the second existed. A prerequisite to all this organization and its successful issue, without overexploiting or devastating the national forests, the ownership of which is - or should be-vested in the peoples of the country, depends upon an adequate forest staff, and a working knowledge by the latter of the whole of the forest areas of the country concerned.

A study of recent annual reports of some of the Colonial Forest Services is by no means so reassuring. In many instances the 'forest factory' is being heavily exploited for war requirements without the requisite safeguards, which are adequate knowledge of the contents of the forests and a sufficient staff to superintend excessive fellings. The capital of the country, which belongs to the people of the country, is consequently being dissipated.

Reference has already been made to the heavy unsupervised fellings being made in the United States in the Douglas fir and companion species, West Coast hemlock, Sitka spruce and Western cedar forests to supply war-time demands (NATURE, 152, 651 ; 1943). Another instance of the same is quoted from Alaska. In the rain-drenched Tongass National Forest of the unknown south-eastern Alaskan panhandle, a forest larger than the State of Western Virginia, is situated what is said to be the world's last great reserve of Sitka spruce, the pre-eminent aircraft timber. Many thousands of these great trees, with a height of $200 \mathrm{ft}$., $80 \mathrm{ft}$. clean bole to first branch and $6 \mathrm{ft}$. diameter at breast height, were felled in 1943 ; the War Production Board, with much of the best forests in Oregon, Washington and British Columbia cut over, having arranged to open out the Alaskan wilderness.

Many examples from recent publications could be culled to show the position the forest occupies in a country in periods of stress when that country can no longer rely on imports of certain staple commodities. The forest at once forms one side of the 'factory'. Without the forest several types of factory, including one of the latest, the plywood factory, would not exist. No commercial man would consider it possible to run a factory in peace- or war-time without the necessary trained supervisory staff to ensure efficient output and a continuity in that output. Any attempts to reduce such staff as redundant would be met with suspicion and a mon possumus. Further, it would be equally recognized that to ensure that a continuity of output is maintained supplies of the necessary raw materials must be available in the amounts already calculated.

How does the 'forest factory' come off in this respect? A study of even the few instances given above serves to show that the position of the forest as regards the supplies it affords to the factory dependent upon it and its relation to that factory is rarely understood. The idea appears to be still held in some quarters that the farest can go on supplying indefinitely the products required from it with a very inadequate supervisory steff, if indeed any such staff is present; wherees the truth is that this type of utilization of the forest results (far quicker in wartime) in its gradual exhaustion, and with the latter the collapse of industries and their man-power dependent upon them. For a forest is a delicate organism and easily ruined by ill-judged fellings.

How is the forest to be maintained and safeguarded? To rehabilitate a forest which has been wastefully and ignorantly exploited, in the absence of expert supervision controlling the work, will take a century or more, if timber is the desideratum. How is a continuity of material from the forest and the consequent continuity of the factories dependent upon it to be maintained ? A trained and expert staff is necessary for the factory. Equally so for the forest. If, as so often in the past in the British Empire, such a staff is only brought in in inadequate numbers after the forests in question have been partially or totally ruined by over-exploitation in one or other of its many possible forms, a long and uphill struggle has to be faced and considerable expense. Trees are not agricultural crops; they require consider. able periods of time to produce what is required; even if only of small size such as pitwood, fuel plantations and so forth. In the absence of a trained staff, an ignorantly exploited forest, if of conifers, may result in the total disappearance of the forest from the area; if of hardwoods, the same may take place, the time elapsing being much longer. But the final results in many cases may be the disappearance of the population which lived in that neighbourhood. Fistory has already witnessed whole populations rnoving to more salubrious parts or gradually dying out owing to the destruction of the neighbouring forests, with the consequent impoverishment of the soils and the diminution of the water supplies. In former times the aftermath of forest destruction and impoverishment of the soils only made its appearance over long periods of time; not so nowadays. With increased populations, with increased methods of rapidly exploiting rich forest areas, and greatly improved methods of transport, a forest can be destroyed, so far as its future usefulness to man is concerned, in a comparatively short time, even in days of peace.

In times of war and stress, an accessible forest and, with expense no object, previously so-termed inaecessible forests, unless under the watchful supervision of their only possible guardians, the trained forest officers, fully acquainted with their regions and in sufficient numbers to enforce correct methods of working, can be exploited and ruined in a very short space, as in the American examples quoted above.

In connexion with the improvident and ignorant utilization of the forest by the populations inhabiting the regions in the past, alluded to above, the presentday consideration being paid to soil conservation schemes both in parts of the Old World and the New merits mention here. Perhaps the most modern examples of the ignorant treatment of forest and agricultural soils is to be seen in the popularly termed 'desert bowls' in the United States and parts of Canada; and also in Australia. As a result, thousands of farmer families have had to emigrate, the once fertile regions having been reduced to desert conditions. But the workd has had for long many older examples, and over wider regions, of this misuse of the land and its vegetation. The British Empire affords many illustrations, of which large stretches in Africa offer examples. This position is at length being considered from the only possible practical aspect, to wit, soil conservation schemesschemes the primary objective of which is to stay the further desiccation and spread of desert conditions, coupled, as they invariably have been, with lessening rainfall and water supplies and the migration of the peoples affected.

Excellent examples of the moderm changed attitude to this question are afforded by the Governments of the Sudan and Kenya. These Governments have epparently realized that soil conservation must be 
approached by bold schenaes, not by small experiments of merely local interest having little reference to the broad requirements of the country affected as a whole. In the Sudan, an active soil conservation policy is under consideration. The sitting committee has adopted, it is understood, a comprehensive programme for which a considerable sum has been earmarked, and which, if and when put into force, will immediately provide employment for a portion of the demobilized native troops. In Kenya, projects of development are foreshadowed. The principal scheme is one for soil conservation, for which it is said a sum of $£ 940,185$ has been allocated.

The forester will indubitably take an active part in this work ; for trained supervision will be essential if money is not to be wasted. One of the forester's jobs will be an endeavour to replace blocks of forest on the ruined and impoverished soils, the primary purpose of which will admittedly be a protective one while assisting in the restoration of the soil water supplies. But as the secondary objective, these forests will in time serve as the factory from which produce will be available to an increasing population returning to a formerly destroyed but now rejuvenated area.

These are neither visions nor dreams. But to understand the job and its possibilities, it will be at least necessary to allow those whose business in life it has been to study, consider, and interpret the factors concerned, to prescribe the possible practical remedial measures to be put into force and, in addition to the necessary funds, to ensure that a trained staff in the necessary numbers is fortheoming.

\section{PRENATAL MORTALITY AND THE BIRTH-RATE}

By DR. A. S. PARKES, F.R.S.

National Institute for Medical Research, London

$\mathbf{M}^{2}$ AXIMUM reproductivity in a monogamous society requires that males and females of appropriate age shall be available in approximately equal numbers. A considerable excess of one sex or the other will decrease the reproduction-rate. In practice, there rarely seems to be an excess of males of this age; among European races a slight excess of females is usual. War, or other events involving a differential toll of men of reproductive age, naturally exaggerate the excess of females. In England and Wales before the War of 1914-18 excess of some 649,000 or $8 \cdot 7$ per cent of females over males, at ages 20-45 years. For several years after 1918 the excess was more than a million, being about $1,050,00 \theta$, or 13.4 per cent in $1925^{2}$. Ten years later, in $1935^{3}$, the effects of the war were disappearing and the excess of females was down to 658,000 , or 7.9 per cent, but it may well increase again considerably as a result of the present War. The surplus women, on statistical grounds alone, are evidently unable to get married in Great Britain, and the great majority of them, therefore, are sociologically sterilized. The number represents an appreciable percentage of the females of reproductive age, and this sociological sterility is a not inconsiderable factor in birth-rate problems. Groome ${ }^{4}$ calculated that an increase in the net reproduction-rate of some 15 per cent would be expected to result from equalizing the numbers of males and females of reproductive age, even without any increase in the total population.

The only immediate solution of this problem of sociological sterility, whether due on a smaller scale to natural causes or on a larger scale to war, lies in a fundamental change in our social conventions. There are, however, other possibilities for a longer term policy. The excess of females is not found at all ages. In England and Wales, about 104 males are born to every 100 females. According to Russell ${ }^{5}$ the mean ratio for $1838-1933$ was $104 \cdot 3$, the range of yearly variation being about 103-106. The highest ratio was recorded in 1919 , and this apparent effect of war conditions is confirmed by evidence from other countries and by the fact that during the present War the ratio has again risen to more than 106. The effect may well, as Martin ${ }^{6}$ suggests, be due to lowering of the age of parents. The excess of males at birth is only temporary. Infant- and childmortality fall differentially on the males, and the excess found at birth is abolished before or early in the reproductive period, and thereafter there is always an excess of females. The reduction in the infant and child mortality-rate has been associated with a raising of the age at which the excess of males disappears and a decrease in the excess of females in later age groups, but it is not certain that this factor will operate any further.

The purpose of this note is to lay emphasis on another aspect of the differential mortality problem, the prenatal wastage of lives, particularly of male lives. The amount of prenatal mortality from the time of conception to the time of birth is known to be considerable in many mammals, figures so high as 40 per cent or more having been determined. In man, the prenatal mortality cannot be estimated with any accuracy, but it is probably at least 20 per cent and may be much higher. Most of the informa. tion then available on this subject was summarized by $\mathrm{me}^{7}$ some years ago.

This prenatal mortality in man will not depress the birth-rate to a corresponding extent, since it must often happen that, where fertility is good, the unsuccessful termination of one pregnancy allows of another one which would not otherwise have occurred. Nevertheless, it must exert a certain influence, and it is clear that a substantial decrease in prenatal mortality would lead to a rise in the birth-rate. More important, however, is the sex incidence of abortions, etc., which has been the subject of a number of researches. The earlier literature is summarized in the review referred to above. Almost all investigators agree that prenatal loss, like infant mortality but more so, falls differentially on the males. Auerbach ${ }^{8}$, for example, found that there were 156 males per 100 females among more than 4,000 foetuses aborted between the fourth and seventh months. The proportion of males was greater among the younger abortions. More recently, Russell ${ }^{5}$ has given figures from American sources in which prenatal deaths under four months included 375 males per 100 females.

Two implications follow from observations such as these. First, it is quite clear that in man, as in some lower mammals, the proportion of males is much higher at conception than at birth. Anything approaching accuracy is impossible in the present state of our knowledge, but it is likely that in man there are at least 120 males to every 100 females at conception. This conclusion is curious in the light of the fact that $X$ - and $Y$-spermatozoa are produced in equal numbers; but various explanations, which 